\title{
Factors associated with drug prescribing practices in long-term care patients with cognitive impairment
}

\author{
Violetta Kijowska ${ }^{1}$ Ilona Barańska · Katarzyna Szczerbińska ${ }^{1}[$
}

Received: 23 January 2020 / Accepted: 30 April 2020 / Published online: 25 May 2020

(c) The Author(s) 2020

\section{Key summary points}

Aim To examine factors related to resident's characteristics which are associated with prescribing anti-dementia medicines, atypical antipsychotics, typical antipsychotics, anxiolytics and other psychostimulants in the individuals with cognitive impairment residing in long-term care institutions.

Findings There are still many long-term care (LTC) residents who receive medications that are not recommended or even contraindicated in dementia. Despite existing clinical recommendations for treatment of cognitive impairment and neuropsychiatric symptoms, the physicians taking care for LTC residents do not follow them properly.

Message Since ca. 70\% of LTC residents have cognitive impairment, all physicians taking care of these patients should be trained in clinical guidelines of dementia treatment.

\begin{abstract}
Purpose To examine factors associated with prescribing anti-dementia medicines (ADM), atypical antipsychotics (A-APM), typical antipsychotics (T-APM), anxiolytics and other psychostimulants (OP) in the residents of long-term care institutions (LTCIs). Methods A cross-sectional survey of a country-representative sample of randomly selected LTCIs in Poland, conducted in 20152016. First, we identified 1035 residents with cognitive impairment (CI) among all 1587 residents. Next, we randomly selected 20 residents from each institution. Study sample consists of 455 residents with CI: 214 recruited from 11 nursing homes and 241 from 12 residential homes. We used InterRAI-LTCF questionnaire and drug dispensary cards administered on the day of data collection to assess use of drugs. Multiple correspondence analysis (MCA), descriptive and logistic regression analyses were performed.

Results The residents were treated with ADM (13.4\%), OP (14.3\%), antipsychotics (46.4\%) including A-APM (24.2\%) and T-APM (27.9\%), and anxiolytics (28.4\%). Hydroxyzine was used most often among anxiolytics (71.3\%). Prescribing of $\mathrm{ADM}$ was more likely in Alzheimer's disease $(\mathrm{OR}=4.378$; 95\% CI 2.173-8.823), while $\mathrm{OP}$ in other dementia $(\mathrm{OR}=1.873$; 95\% CI 1.007-3.485). Administration of A-APM was more likely in older residents ( $\mathrm{OR}=1.032,95 \% \mathrm{CI} 1.009-1.055)$, and when delusions appeared $(\mathrm{OR}=2.082$; 95\%CI 1.199-3.613), while there were no neuropsychiatric factors increasing the odds of T-APM use. Prescribing of anxiolytics was less likely in moderate CI (by $47.2 \%$ ) than in residents with mild CI. Conclusion Current practices of prescribing psychotropics are inadequate in Polish LTCIs, especially in terms of use of T-APM and hydroxyzine. More attention should be given to motivate physicians to change their prescribing practices.
\end{abstract}

Keywords Cognitive impairment $\cdot$ Antipsychotics $\cdot$ Antianxiety agents $\cdot$ Nursing homes $\cdot$ Residential facilities $\cdot$ InterRAILTCF tool

Electronic supplementary material The online version of this article (https://doi.org/10.1007/s41999-020-00331-0) contains supplementary material, which is available to authorized users.

Katarzyna Szczerbińska

katarzyna.szczerbinska@uj.edu.pl

1 Laboratory for Research on Aging Society, Department of Sociology of Medicine, Chair of Epidemiology and Preventive Medicine, Jagiellonian University Medical College, Kopernika 7a Street, 31-034 Kraków, Poland

$\begin{array}{ll}\text { Abbreviations } \\ \text { AChEI } & \text { Acetylcholinesterase inhibitors } \\ \text { AD } & \text { Alzheimer's disease } \\ \text { ADL } & \text { Activities of daily living } \\ \text { ADM } & \text { Anti-dementia medicines } \\ \text { APM } & \text { Antipsychotic medicines } \\ \text { ATC } & \begin{array}{l}\text { The anatomical therapeutic chemical } \\ \text { classification }\end{array} \\ \text { A-APM } & \text { Atypical antipsychotic medicines }\end{array}$




$\begin{array}{ll}\text { CI } & \text { Cognitive impairment } \\ \text { CMS } & \begin{array}{l}\text { The Centers for Medicare and Medicaid } \\ \text { Services }\end{array} \\ \text { CPS } & \text { Cognitive performance scale } \\ \text { DLB } & \text { Lewy body dementia } \\ \text { ICD-code } & \text { International classification of diseases } \\ \text { LE } & \text { Life expectancy } \\ \text { LTC } & \text { Long-term care } \\ \text { LTCI } & \text { Long-term care institution } \\ \text { MCA } & \text { Multiple correspondence analysis } \\ \text { NH } & \text { Nursing home } \\ \text { NHF } & \text { National Health Fund } \\ \text { NMDA } & \text { The } N \text {-methyl-D-aspartate receptor antagonist } \\ \text { NPSs } & \text { Neuropsychiatric symptoms } \\ \text { OP } & \text { Other psychostimulants (i.e. medicines } \\ & \text { improving blood perfusion in the brain, but } \\ & \text { not indicated in dementia-N06BX, N07CA) } \\ \text { RH } & \text { Residential home } \\ \text { SHELTER } & \text { Services and Health for Elderly in Long- } \\ & \text { TERm care (SHELTER) } \\ \text { T-APM } & \text { Atypical antipsychotic medicines } \\ \text { VaD } & \text { Vascular dementia }\end{array}$

\section{Introduction}

Dementia is a major neurocognitive disorder predominated by symptoms of cognitive function impairment, and often accompanied with neuropsychiatric symptoms (NPSs) [1, 2]. Pharmacological treatment of dementia essentially focuses on the treatment of these two groups of symptoms through the use of anti-dementia (ADM) and antipsychotic medicines (APM). During the last 2 decades, treatment of this disorder evolved towards the use of ADM (e.g. donepezil, rivastigmine, memantine) and atypical antipsychotic drugs (A-APM) (e.g. quetiapine, risperidone, olanzapine), which gradually replace nootropic drugs (e.g. piracetam, vinpocetine), typical antipsychotics (T-APM) (e.g. haloperidol, promazine) and benzodiazepines. The latter, due to side effects, are currently not recommended for older people [3]. In light of ongoing discussions on the excessive use of medicines and the accumulation of adverse effects in older adults, a rational approach to treating these disorders in long-term care (LTC) residents is particularly relevant. It is also important, because the prevalence of cognitive impairment (CI) in these settings is very high, reaching about 60-70\% in most European [4] and Northern American countries [5], as well as in Poland [6]. Patients with CI are the main group of residents taking psychotropic drugs in nonpsychiatric institutions. The way they are treated affects not only their quality of life and health status
[7-9], but also the economic results of the institutions they are residing in $[10,11]$.

In Poland, there are two types of LTC institutions (LTCIs): residential homes (RH) served by off-site general practitioners (GP) and nursing homes (NH) with physicians (with various specializations) employed for $24 \mathrm{~h}$ per 7 days a week. These facilities are organized and funded on a different basis (described elsewhere) [12], where prescribing and administering of medicines are organized differently (supplemental Table 1). Patients with CI may be equally referred to RHs and NHs, however, due to the diverse range of services provided in these facilities, treatment of CI may differ between them.

The main aim of this study was to describe the current practices of pharmacological treatment of residents with CI in LTCIs, with a focus on:

- identifying patterns of inappropriate prescribing in reference to the level of $\mathrm{CI}$ and the type of setting $(\mathrm{NH}$ and $\mathrm{RH}$ ), and

- identifying predictors of prescribing specific drugs classes.

To achieve these goals, we have conducted:

- a comparison of use of certain drug classes in light of data from international studies;

- a comparison of prescription of anti-dementia medications (ADM) and treatment with other psychostimulants (OP);

- a comparison of prescription of typical (T-APM) and atypical antipsychotic medicines (A-APM);

- a logistic regression analysis to find factors associated with administering ADM, T-APM, A-APM, anxiolytics and OP;

- a multiple correspondence analysis (MCA) to check which classes of psychotropic drugs are jointly prescribed in LTC residents depending on the resident's age, the level of CI, and the type of facility, they reside.

\section{Methods}

\section{Settings and participants}

The study was performed in 2015-2016 within 23 LTC institutions in Poland, randomly selected in all 6 regions in terms of size, status, geographical region, number of beds and facility type: NH, which is similar to a skilled nursing facility, and $\mathrm{RH}$ - a residential facility referring to the classification proposed by experts' panel in JAMDA in 2015 [13]. A detailed description of inclusion criteria to the study [6] and a comparison of both types of the facilities have been published elsewhere [12]. The study received approval 
from the relevant University Ethics Committee (decision No. 122.6120.31.2015).

\section{Study design}

From a total of 1587 residents admitted to 23 facilities, we excluded 93 individuals who were unable to express any cognitive or neuropsychiatric symptoms (NPSs) due to indiscernible consciousness or coma. In the first stage of the study, we identified 1035 residents with CI based on Cognitive Performance Scale (CPS) [14] score with a cutoff of 2 points. Next, 20 residents with CI were randomly selected from each facility and included in a study group of 455 residents who were then studied with the interRAI-LTCF questionnaire (interRAI Long-Term Care Facilities Assessment System questionnaire)—a validated and widely used tool enabling comprehensive geriatric assessment of people receiving LTC services [15]. LTC residents were assessed by regular staff at each institution-a nurse or a psychologist-who passed standardized training performed by one researcher as specified in the user's manual of the interRAILTCF tool [16]. The assessments were done mainly on the basis of a 3-day observation of the residents, and supported (if necessary) by data obtained from medical files, family members or other staff. The study protocol and comprehensive characteristics of the study group has been described in detail elsewhere [6, 12].

\section{Measurements}

A seven-point CPS scale, embedded in interRAI-LTCF instrument, was used to assess $\mathrm{CI}$ as mild $(\mathrm{CPS}=2)$, moderate (CPS $=3-4)$ or severe (CPS $=5-6)$. This is a widely used scale [17, 18], which demonstrated a high correlation with the Mini-Mental State Examination (MMSE) [14, 19], the Montreal Cognitive Assessment (MoCA) [17], and the Test for Severe Impairment, nursing judgments of disorientation, and neurological diagnoses of Alzheimer's disease (AD) and other dementias [14] in LTC residents. A sevenpoint Activities of Daily Living Hierarchy scale (ADLh), measuring functional performance based on four items: personal hygiene, locomotion, toilet use and eating, categorized the LTC residents as independent (ADLh $=0-1$ ); moderately dependent (ADLh $=2-3)$, and severely dependent $(\mathrm{ADLh}=4-6)$ [20]. We also applied the four-item Aggressive Behavior Scale (ABS) to measure verbal and physical abuse, socially inappropriate behavior, and resistance to care, as well as we considered each of these variables separately. The $\mathrm{ABS}$ ranges from 0 to 12 , where a higher score indicates a greater frequency of aggressive behavior [21]. Depression symptoms were evaluated using the seven-item
Depression Rating Scale (DRS), which indicates probable depression, when its score is 3 and higher [22].

The analyses in this paper were conducted with focus on comparing drug use by residents in NHs and RHs. Data were collected from drug dispensary cards on the day of data collection. We used the Anatomical Therapeutic Chemical (ATC) classification [23] to group medicines as following: anti-dementia medicines (ADM) (N06DA, N06DX), other psychostimulants (OP) (N06BX), atypical antipsychotics (A-APM) (N05AH, N05AX), typical antipsychotics (T-APM) (N05AA, N05AB, N05AD, N05AF, N05AL), and anxiolytics (N05BA, N05BB, N05CD, N05CF).

\section{Statistical analysis}

A detailed list of medications with their use by residents depending on the type of institution ( $\mathrm{RH}$ or $\mathrm{NH}$ ) is shown in Table 2. In the Table 1, we presented relationships between the use of selected ATC groups of drugs and the resident characteristics (differences were assessed using the $\mathrm{Chi}^{2}$ test). In our analyses, we carefully selected the variables including: demographic factors (age, gender); type of setting (due to differences in care organization and access to physician); severity of CI and level of ADL; factors which may trigger use of psychotropic medicines such as: psychotic symptoms (hallucinations, delusions), behavior problems (agitation, wandering, verbal and physical abuse, resistance to care); depression, psychiatric illness, Alzheimer's disease and other dementia, which may cause indications for use of these drugs; and use of restrictive devices as they might be associated with administering pharmacologic restraints. All these variables were checked consecutively in the univariate analysis and logistic regression analysis for their associations with the use of drugs from particular ATC classes to determine residents' characteristics associated with their prescribing (Table 3). The variable of ADL level was excluded due to collinearity with the CPS level. Some associations occurred to be not straightforward, but more complex, and are presented as interactions between variables. They are result of careful following the principles of performing logistic regression analysis. The way how they were calculated had been shown in Table 3, and described how they should be interpreted in the results section.

The logistic regression analyses provided information on the predictors of prescribing a single drug classes. However, in the reality, these drugs are often used together. Therefore, we have also carried out a Multiple Correspondence Analysis (MCA) which belongs to a family of descriptive methods, that allows to investigate the correlation between several categorical interdependent variables, measuring the level of inertia among them. It provides a general view of relationships between variables when simple cross-tabulations of numerous variables become complex and difficult to interpret. We used 


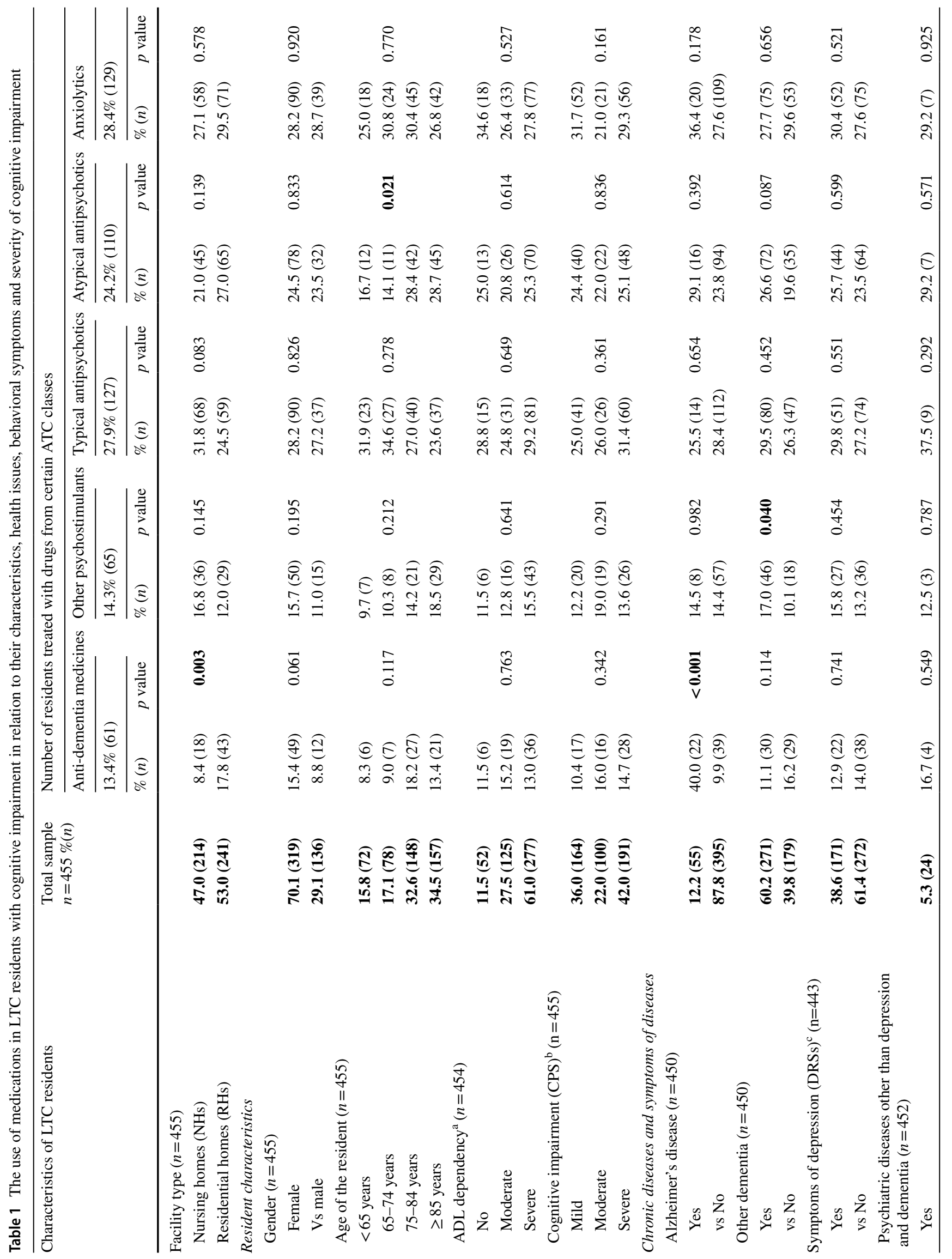




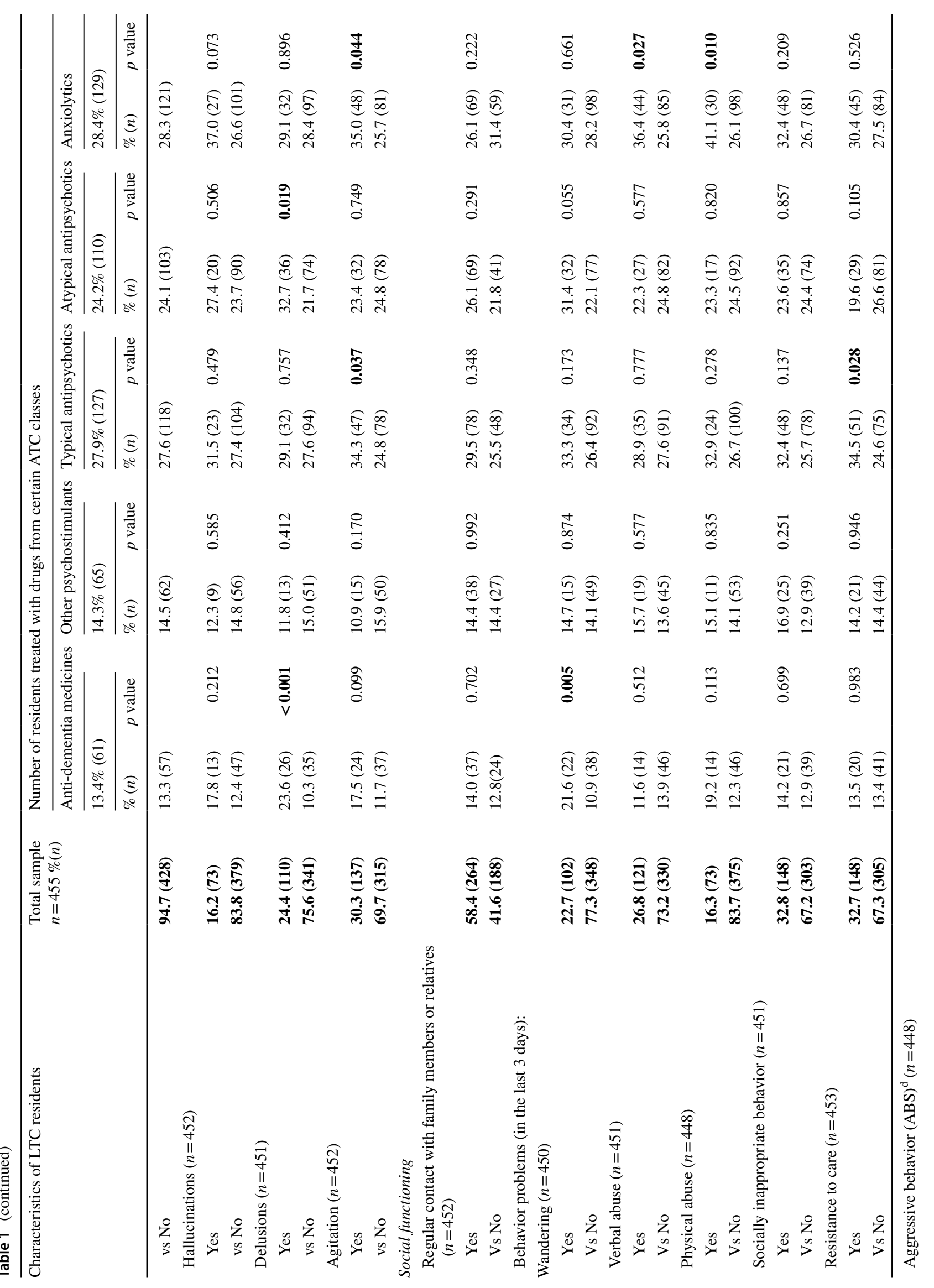




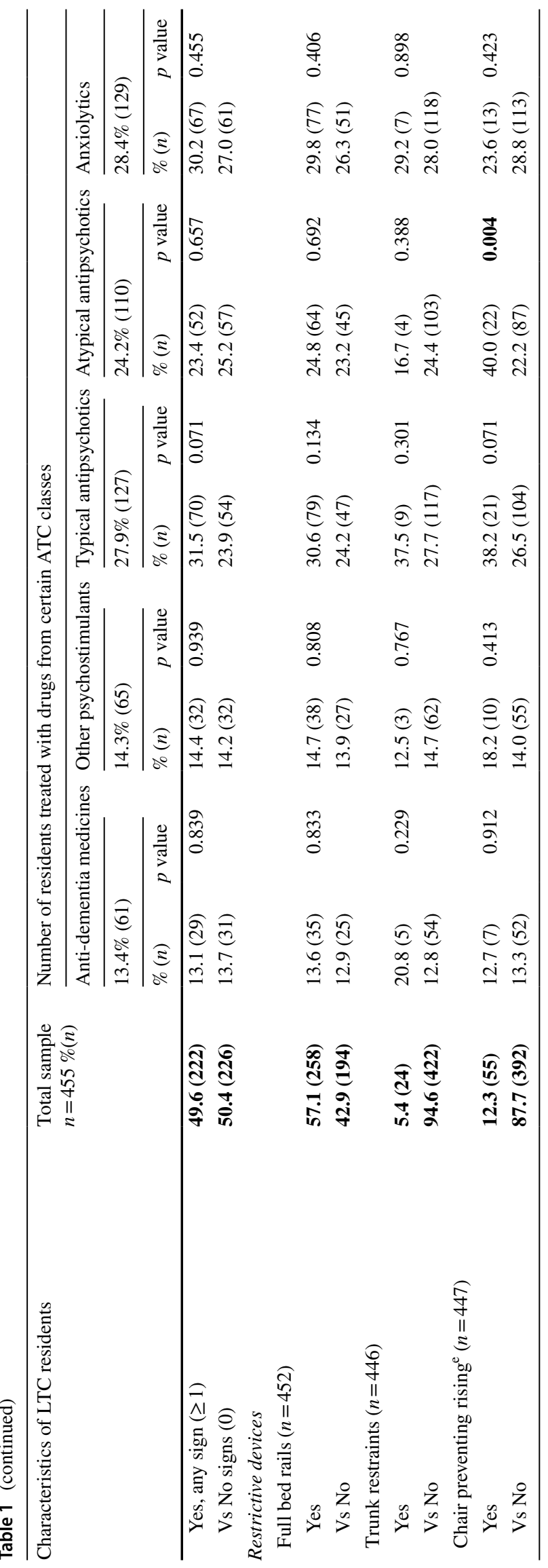

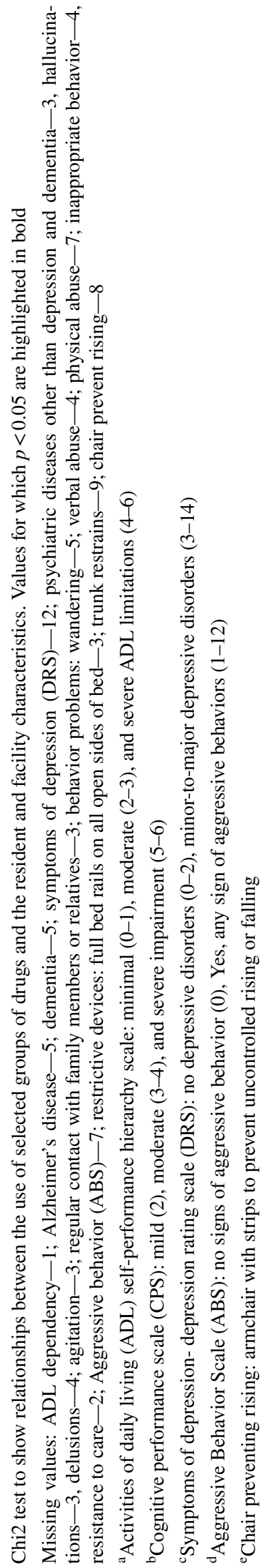


Fig. 1 Multiple correspondence analysis plot for two dimensions of the use of different medications in LTC residents with cognitive impairment $(\mathrm{CI})$ in relation to the facility type, resident's age and the level of CI

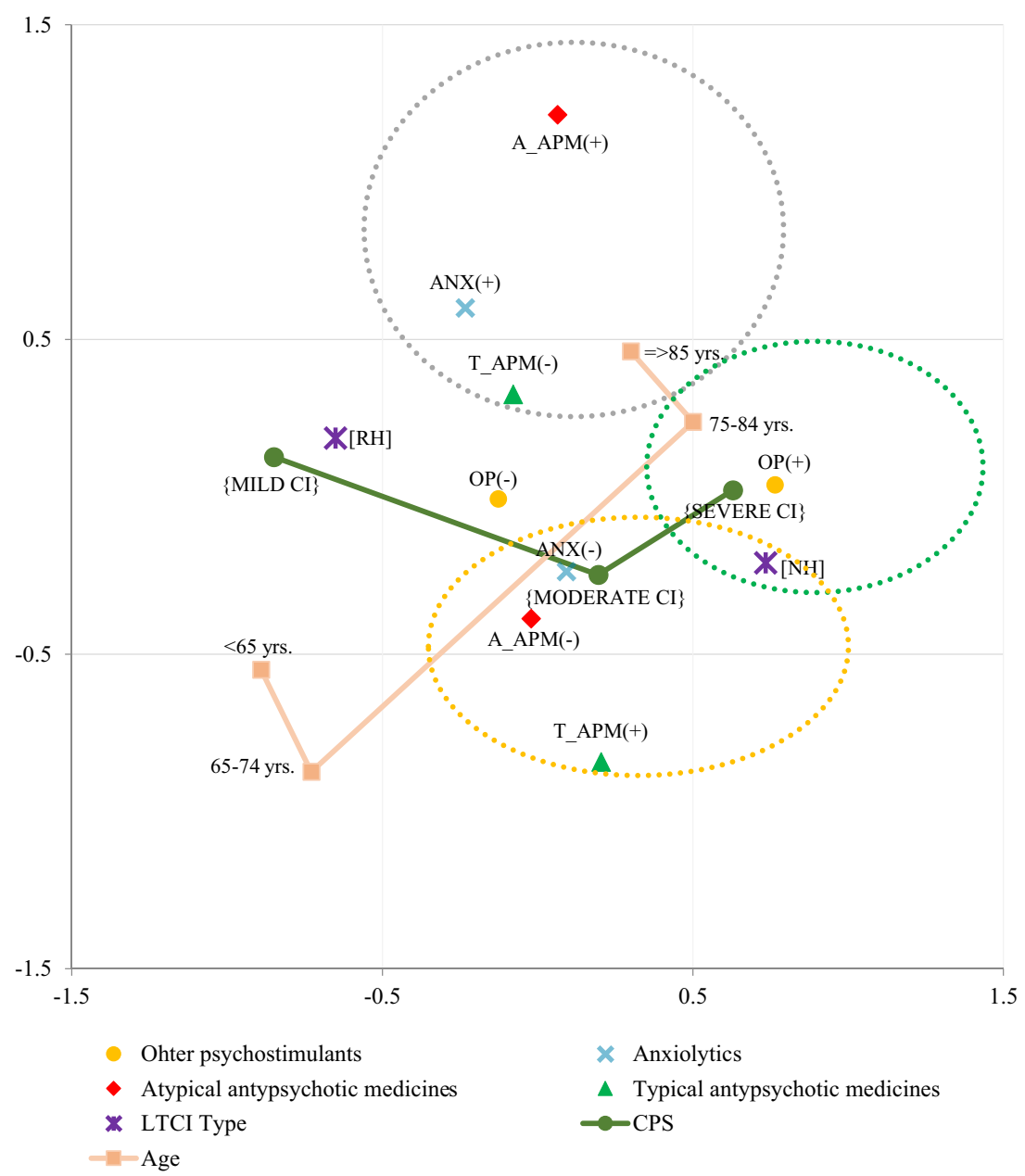

this analysis to explore the relationships between the use of drugs and the variables characterizing the residents (Fig. 1). First, we considered information about use of psychotropics from particular ATC classes as well as basic characteristics of the resident presented in Table 1 (age, gender, type of facility, ADL, CPS). Gender and ADL variables had very low values of discriminatory measures on both dimensions, so they were removed from the analysis. We also excluded ADM from the MCA, because this variable was strongly correlated with presence of Alzheimer's disease. Finally, we identified two dimensions (axes), and seven variables (A-APM, T-APM, anxiolytics, OP, LTCI type, level of CI and resident's age), the most correlated with each dimension. In MCA, the squared correlations between variables and the dimensions are used as coordinates. The distance between any row points or column points gives a measure of their similarity (or dissimilarity). The variables the most related to each other are focused in a group together, whilst dissimilarity, on the other hand, results in a distance. Negatively correlated variables are positioned on opposite sides of the plot origin (opposed quadrants).

By applying MCA, we explored the correlation between use the certain psychotropic drug classes (A-APM, T-APM,
OP and anxiolytics) in controlling certain resident's characteristics such as: age, CPS level and facility type. The figure above helps to identify seven variables (CI level, resident's age, type of facility, use of drugs from ATC classes: A-APM, T-APM, OP and anxiolytics) that are the most correlated with each dimension. The squared correlations between variables and the dimensions are used as coordinates. The distance between any row points or column points gives a measure of their similarity (or dissimilarity). Variables that make up the group are focused in a group together, whilst dissimilarity, on the other hand, results in a distance. Negatively correlated variable categories are positioned on opposite sides of the plot origin (opposed quadrants). Legend: $\mathrm{NH}$ nursing home, $R H$ residential home, mild $C I$ mild cognitive impairment, moderate CI moderate cognitive impairment, severe $C I$ severe cognitive impairment, $T \_A P M$ typical antipsychotics, $A \_A P M$ atypical antipsychotics, $O P$ other psychostimulants, $A N X$ anxiolytics. Plus $(+)$ means that the patient received a particular drug, whereas minus $(-)$ means no usage of particular drug. 
Analyses were performed with SPSS 25 for Windows. Differences were considered statistically significant if $p$ value was less than 0.05 .

\section{Results}

\section{Resident characteristics and use of drugs}

The residents with $\mathrm{CI}$ in our study were diagnosed for $\mathrm{AD}$ (ICD-coded with G.30) (12.2\%) or other dementia (60.2\%) (ICD-coded with F01, F02 or F03), had symptoms of depression $(38.6 \%)$ or psychiatric diseases other than depression and dementia (5.3\%). More than $70 \%$ residents were female, and $42.0 \%$ had severe CI, while $88.5 \%$ were moderate-toseverely dependent in ADL (Table 1). They were treated with ADM (13.4\%), OP (14.3\%), any antipsychotics (46.4\%) and anxiolytics (28.4\%). We found that ADM were significantly more often administered to $\mathrm{RH}$ residents $(17.8 \%)$ than to $\mathrm{NH}$ patients $(8.4 \%)$, while prescribing of A-APM was more frequent in older patients at the age 75 years and older (approx. 30\%). There was no impact of gender, neither ADL dependency, nor level of CI on frequency of medication use. However, some health conditions (AD, other dementia), symptoms (delusions, agitation), and behavior problems (wandering, verbal and physical abuse, resistance to care) showed association with significantly higher use of the aforementioned medicines. The use of chair preventing rising was associated with almost twice the higher use of A-APM.

The comparison between types of facilities did not show significant differences in use of certain drugs classes or substances with the exception of donepezil, rivastigmine, and olanzapine, which were more frequent in $\mathrm{RH}$ residents with CI (as shown in Table 2). It is worth noting that some of the drugs were prescribed more often than the others, e.g. donepezil in $7.7 \%$ of residents (among ADM), quetiapine in $15.4 \%$ individuals (among A-APM), perazine (10.1\%), promazine (7.9\%) and haloperidol (7.5\%) (among T-APM) and hydroxyzine (in $20.2 \%$ residents) (among anxiolytics).

\section{Factors associated with prescribing medicines from certain therapeutic classes}

Upon logistic regression analysis (Table 3), we found that RH residents had 2.88 times higher chance to be administered ADM (donepezil, rivastigmine or memantine) compared to patients in NHs. Moreover, AD (OR =4.378, 95\%CI 2.173-8.823) and hallucinations or delusions $(\mathrm{OR}=2.244,95 \% \mathrm{CI} 1.170-4.306)$ significantly increased the chance of taking these drugs.

On the contrary, prescribing of OP (piracetam or vinpocetine) was $87 \%$ more likely in patients with dementia other than $\mathrm{AD}$ and almost twice less likely in the residents of RHs. Moreover, in RHs, as the age of a resident increases by 1 year, the chance they are administered OP increases by $4 \%$ (the method of calculating the interaction effect is shown in Table 3).

We found that dementia other than $\mathrm{AD}(\mathrm{OR}=1.520$, 95\% CI 1.016-2.273) and use of chair preventing rising (to protect uncontrolled getting up and fall) $(\mathrm{OR}=2.466$; 95\% CI 1.272-4.780) were associated with an increased use of antipsychotics in general. However, factors associated with use of typical or atypical antipsychotics differed. T-APM were administered to $27.9 \%$ of residents, but none of the analyzed factors were associated with their prescribing, except older age which decreased odds ratio $(\mathrm{OR}=0.975$; 95\% CI 0.957-0.994). On the contrary, the chance of being treated with A-APM (used by $24.2 \%$ residents) was significantly higher in older patients $(\mathrm{OR}=1.032 ; 95 \% \mathrm{CI}$ 1.009-1.055) and individuals with delusions $(\mathrm{OR}=2.082$, 95\% CI 1.199-3.613). The residents who resisted to care had a lower risk (by 54.9\%) to be administered A-APM, but higher, although not significant risk of receiving T-APM.

Residents with moderate CI were nearly twice less likely (by $47.2 \%$ ) to receive anxiolytics compared to those with mild CI. Hydroxyzine was the most often used (71.3\%) among anxiolytics; therefore, we conducted multivariable regression analysis for this single drug. Severe CI (compared to mild CI) increased the chance of receiving this drug 2.6 times in patients presenting aggressive behavior disorders (assessed with ABS). The use of physical restraints (especially full bed rails) was high (Table 1). Therefore, we conducted logistic regression analysis using them all together as one variable and each of them separately, but did not prove their association with prescribing of any of analyzed psychotropics class.

\section{Psychotropic drugs prescribing patterns in LTC residents}

Next, we checked whether there was a correlation between the use of selected classes of psychotropic drugs and the type of facility, level of CI and resident's age. By applying MCA, we identified two dimensions (axes), which explained a $37.06 \%$ improved estimate of the inertia among the seven factors (CI level, resident's age, type of facility, use of drugs from ATC classes: A-APM, T-APM, OP and anxiolytics). For the first factorial axis (axis $X$ ), the principal discrimination measures were associated with LTCI type (0.478) and CI level (0.434). For the second axis (axis $Y$ ), the discrimination measures were those mostly associated with using or not A-APM (0.470). In the result of MCA, we identified three groups of residents. The first group (marked in the green circle) consisted of the individuals with severe CI, more frequently aged 75-84 years, residing in $\mathrm{NH}$, and taking OP treatment. The second group (marked with the gray circle) contained patients who more often received A-APM and anxiolytics but less often T-APM, and that way of treatment was applied mostly to the oldest individuals at the age 
Table 2 The use of certain medicine substances and drug classes in residents with cognitive impairment in relation to the type of LTC institution

\begin{tabular}{|c|c|c|c|c|c|c|c|}
\hline \multirow[t]{2}{*}{ Group } & \multirow[t]{2}{*}{ Sub-group } & \multirow[t]{2}{*}{ ATC code $^{a}$} & \multicolumn{5}{|l|}{ List of drugs } \\
\hline & & & Name & $\begin{array}{l}\text { Total sample } \\
\%(n)\end{array}$ & $\begin{array}{l}\text { Nursing home }(\mathrm{NH}) \\
\%(n)\end{array}$ & $\begin{array}{l}\text { Residential } \\
\text { home }(\mathrm{RH}) \\
\%(n)\end{array}$ & $p$ value \\
\hline \multirow{3}{*}{$\begin{array}{l}\text { Anti-dementia medi- } \\
\text { cines } 13.4 \%(61)\end{array}$} & \multirow{3}{*}{$\begin{array}{l}\text { Anti-dementia drugs } \\
\text { (N06D) }\end{array}$} & N06DA02 & Donepezil & $7.7(35)$ & $4.7(10)$ & $10.4(25)$ & 0.023 \\
\hline & & N06DA03 & Rivastigmine & $2.6(12)$ & $0.5(1)$ & $4.6(11)$ & 0.006 \\
\hline & & N06DX01 & Memantine & $5.5(25)$ & $5.6(12)$ & $5.4(13)$ & 0.921 \\
\hline \multirow{2}{*}{$\begin{array}{l}\text { Other psychostimulants } \\
14.3 \%(65)\end{array}$} & \multirow{2}{*}{$\begin{array}{l}\text { Other psychostimulants, } \\
\text { (N06BX) }\end{array}$} & N06BX03 & Piracetam & $8.4(38)$ & $9.8(21)$ & $7.1(17)$ & 0.288 \\
\hline & & N06BX18 & Vinpocetine & $7.0(32)$ & $8.4(18)$ & $5.8(14)$ & 0.279 \\
\hline \multirow{12}{*}{$\begin{array}{l}\text { Antipsychotics } 46.4 \% \\
\text { (211) }\end{array}$} & \multirow{3}{*}{$\begin{array}{l}\text { Atypical antipsychotics } \\
\text { (N05A) }\end{array}$} & N05AH03 & Olanzapine & $4.0(18)$ & $1.4(3)$ & $6.2(15)$ & 0.008 \\
\hline & & N05AH04 & Quetiapine & $15.4(70)$ & $15.0(32)$ & $15.8(38)$ & 0.810 \\
\hline & & N05AX08 & Risperidone & $7.3(33)$ & $6.1(13)$ & $8.3(20)$ & 0.361 \\
\hline & \multirow{9}{*}{$\begin{array}{l}\text { Typical antipsychotics } \\
\text { (N05A) }\end{array}$} & N05AL01 & Sulpiride & $1.1(5)$ & $0.5(1)$ & $1.7(4)$ & 0.377 \\
\hline & & N05AL03 & Tiapride & $2.2(10)$ & $2.3(5)$ & $2.1(5)$ & 1.000 \\
\hline & & N05AD01 & Haloperidol & $7.5(34)$ & $7.5(16)$ & $7.5(18)$ & 0.997 \\
\hline & & N05AA02 & Levomepromazine & $1.3(6)$ & $1.4(3)$ & $1.2(3)$ & 1.000 \\
\hline & & N05AA03 & Promazine & $7.9(36)$ & $9.3(20)$ & $6.6(16)$ & 0.286 \\
\hline & & N05AB10 & Perazine & $10.1(46)$ & $12.1(26)$ & $8.3(20)$ & 0.174 \\
\hline & & N05AF01 & Flupentixol & $0.4(2)$ & - & $0.8(2)$ & 0.501 \\
\hline & & N05AF013 & Chlorprothixene & $0.9(4)$ & $0.5(1)$ & $1.2(3)$ & 0.626 \\
\hline & & N05AF05 & Zuclopenthixol & $0.7(3)$ & $1.4(3)$ & - & 0.103 \\
\hline \multirow[t]{12}{*}{ Anxiolytics $28.4 \%$ (129) } & \multirow[t]{5}{*}{ Anxiolytics (N05B) } & N05BA01 & Diazepam & $2.0(9)$ & $3.3(7)$ & $0.8(2)$ & 0.090 \\
\hline & & N05BA04 & Oxazepam & $0.4(2)$ & $0.9(2)$ & - & 0.221 \\
\hline & & N05BA06 & Lorazepam & $0.9(4)$ & $0.9(2)$ & $0.8(2)$ & 1.000 \\
\hline & & N05BA12 & Alprazolam & $1.1(5)$ & $0.5(1)$ & $1.7(4)$ & 0.377 \\
\hline & & N05BB01 & Hydroxizine & $20.2(92)$ & $18.7(40)$ & $21.6(52)$ & 0.444 \\
\hline & \multirow{7}{*}{$\begin{array}{l}\text { Hypnotics and sedatives } \\
\text { (N05C) }\end{array}$} & N05CD02 & Nitrazepam & $0.7(3)$ & $0.9(2)$ & $0.4(1)$ & 0.603 \\
\hline & & N05CD04 & Estazolam & $3.1(14)$ & $3.3(7)$ & $2.9(7)$ & 0.821 \\
\hline & & N05CD06 & Lormetazepam & $0.2(1)$ & - & $0.4(1)$ & 1.000 \\
\hline & & N05CD07 & Temazepam & $0.2(1)$ & - & $0.4(1)$ & 1.000 \\
\hline & & N05CD08 & Midazolam & $0.2(1)$ & - & $0.4(1)$ & 1.000 \\
\hline & & N05CF01 & Zopiclone & $0.9(4)$ & - & $1.7(4)$ & 0.126 \\
\hline & & N05CF02 & Zolpidem & $0.9(4)$ & $0.5(1)$ & $1.2(3)$ & 0.626 \\
\hline
\end{tabular}

$\mathrm{Chi}^{2}$ test used. Values for which $p<0.05$ are highlighted in bold

${ }^{\mathrm{a}} A T C$ the Anatomical Therapeutic Chemical Classification

85 years or older. The third one (marked with the yellow circle) included individuals more often taking T-APM, and less frequently anxiolytics and A-APM, who were residents with moderate $\mathrm{CI}$ residing in $\mathrm{NH}$ (Fig. 1).

\section{Discussion}

\section{Use of anti-dementia medicines (donepezil, rivastigmine, memantine) and other psychostimulants}

In our study, the use of ADM was less prevalent in Polish LTCIs (13.4\%) compared to US [24], where 30\% of any type dementia residents were administered acetylcholinesterase inhibitors (AChEIs). It was a little higher than in the European SHELTER study (11.6\% residents with severe CI), yet our study was conducted 5 years after SHELTER one, when prescribing of ADM has become more common. It has been improved in our country after including donepezil and transdermal rivastigmine on the "list of drugs for seniors 75+" allowing patients with AD diagnosis (ICD-coded G30) to receive these drugs free of charge, but patients with a diagnosis of other dementia (ICD-codes: F01, F02, F03) could not get any discount. Therefore, in our study, patients with dementia other than $\mathrm{AD}$ were more likely to receive cerebral vasodilators and nootropic drugs (e.g. piracetam, vinpocetine), despite these medicines not being recommended in 
Table 3 Factors associated with prescribing psychotropics from certain ATC classes in LTC residents with cognitive impairment—-the results of univariable and multivariable regression analyses

\begin{tabular}{|c|c|c|c|c|}
\hline & \multicolumn{2}{|c|}{$\begin{array}{l}\text { Univariable logistic regression } \\
\text { model }\end{array}$} & \multicolumn{2}{|c|}{$\begin{array}{l}\text { Multivariable logistic regression } \\
\text { model }\end{array}$} \\
\hline & OR $(95 \% \mathrm{CI})$ & $p$ value & OR $(95 \% \mathrm{CI})$ & $p$ value \\
\hline \multicolumn{5}{|l|}{ Anti-dementia medicines } \\
\hline Facility type $^{\mathrm{a}}(\mathrm{NH}$, ref.) & $2.365(1.318-4.243)$ & 0.004 & $2.875(1.491-5.542)$ & 0.002 \\
\hline Gender (female, ref.) & $0.533(0.274-1.038)$ & 0.064 & $0.882(0.412-1.888)$ & 0.747 \\
\hline Age & $1.023(0.998-1.048)$ & 0.071 & $1.012(0.983-1.042)$ & 0.426 \\
\hline Alzheimer's disease (No, ref.) & $6.085(3.232-11.457)$ & $<0.001$ & $4.378(2.173-8.823)$ & $<0.001$ \\
\hline Hallucinations or delusions (No, ref.) & $2.651(1.523-4.614)$ & 0.001 & $2.244(1.170-4.306)$ & 0.015 \\
\hline Wandering (No, ref.) & $2.243(1.256-4.006)$ & 0.006 & $1.154(0.587-2.265)$ & 0.678 \\
\hline Mild $\mathrm{CI}^{\mathrm{b}}$ (ref.) & 1 & & 1 & \\
\hline Moderate $\mathrm{CI}^{\mathrm{b}}$ & $1.647(0.791-3.430)$ & 0.182 & $1.261(0.557-2.854)$ & 0.578 \\
\hline Severe $\mathrm{CI}^{\mathrm{b}}$ & $1.485(0.781-2.824)$ & 0.227 & $1.421(0.687-2.940)$ & 0.343 \\
\hline Constant & & & $0.014(0.001-0.169)$ & 0.001 \\
\hline \multicolumn{5}{|l|}{ Other psychostimulants } \\
\hline Facility type $^{\mathrm{a}}$ (NH ref.) & $0.676(0.399-1.147)$ & 0.147 & $0.537(0.298-0.967)$ & $\mathbf{0 . 0 3 8}$ \\
\hline Gender (female ref.) & $0.667(0.360-1.234)$ & 0.197 & $0.800(0.408-1.569)$ & 0.516 \\
\hline Age (78 years) & $1.022(0.998-1.047)$ & 0.072 & $0.980(0.947-1.015)$ & 0.252 \\
\hline Facility type $x$ Age & - & - & $1.064(1.011-1.121)$ & 0.018 \\
\hline Mild $\mathrm{CI}^{\mathrm{b}}$ (ref.) & 1 & & 1 & \\
\hline Moderate $\mathrm{CI}^{\mathrm{b}}$ & $1.689(0.852-3.348)$ & 0.133 & $1.433(0.701-2.927)$ & 0.324 \\
\hline Severe $\mathrm{CI}^{\mathrm{b}}$ & $1.135(0.608-2.118)$ & 0.692 & $0.767(0.393-1.497)$ & 0.437 \\
\hline Other dementia (No, ref.) & $1.829(1.023-3.270)$ & 0.042 & $1.873(1.007-3.485)$ & 0.047 \\
\hline Socially inappropriate behavior (No, ref.) & $1.376(0.797-2.375)$ & 0.252 & $1.428(0.808-2.525)$ & 0.220 \\
\hline Constant & & & $0.137(0.065-0.292)$ & $<0.001$ \\
\hline \multicolumn{5}{|c|}{ Effect of interaction: facility type $(R H) \times$ age: $1.064 \times 0.980=1.043$. It means a $4 \%$ higher chance } \\
\hline \multicolumn{5}{|l|}{ Typical antipsychotics } \\
\hline Facility type $^{\mathrm{a}}$ (NH ref.) & $0.696(0.461-1.050)$ & 0.084 & $0.761(0.464-1.246)$ & 0.277 \\
\hline Gender (female ref.) & $0.951(0.607-1.491)$ & 0.826 & $0.898(0.534-1.511)$ & 0.686 \\
\hline Age & $0.981(0.965-0.998)$ & 0.026 & $0.975(0.957-0.994)$ & 0.009 \\
\hline Mild CI ${ }^{\mathrm{b}}$ (ref.) & 1 & & 1 & \\
\hline Moderate $\mathrm{CI}^{\mathrm{b}}$ & $1.054(0.596-1.863)$ & 0.856 & $1.002(0.551-1.822)$ & 0.995 \\
\hline Severe $\mathrm{CI}^{\mathrm{b}}$ & $1.374(0.961-2.192)$ & 0.183 & $1.122(0.661-1.904)$ & 0.669 \\
\hline Psychiatric disease $^{c}$ (No, ref.) & $1.576(0.672-3.700)$ & 0.296 & $1.526(0.625-3.729)$ & 0.354 \\
\hline Agitation (No, ref.) & $1.587(1.026-2.453)$ & 0.038 & $1.296(0.769-2.185)$ & 0.330 \\
\hline Regular contact with family (No, ref.) & $1.223(0.803-1.864)$ & 0.349 & $1.091(0.671-1.774)$ & 0.725 \\
\hline Chair preventing rising ${ }^{\mathrm{e}}$ (No, ref.) & $1.710(0.950-3.081)$ & 0.074 & $1.394(0.708-2.743)$ & 0.337 \\
\hline Wandering (No, ref.) & $1.391(0.865-2.239)$ & 0.174 & $1.269(0.745-2.163)$ & 0.380 \\
\hline Resistance to care (No, ref.) & $1.612(1.051-2.473)$ & 0.029 & $1.355(0.812-2.261)$ & 0.246 \\
\hline Constant & & & $2.190(0.430-11.165)$ & 0.346 \\
\hline \multicolumn{5}{|l|}{ Atypical antipsychotics } \\
\hline Facility type $^{\mathrm{a}}$ (NH ref.) & $1.387(0.898-2.142)$ & 0.140 & $1.428(0.893-2.282)$ & 0.137 \\
\hline Gender (female ref.) & $0.951(0.593-1.523)$ & 0.833 & $1.318(0.773-2.247)$ & 0.310 \\
\hline Age & $1.027(1.008-1.048)$ & 0.007 & $1.032(1.009-1.055)$ & 0.006 \\
\hline Mild $\mathrm{CI}^{\mathrm{b}}$ (ref.) & 1 & & 1 & \\
\hline Moderate $\mathrm{CI}^{\mathrm{b}}$ & $0.874(0.484-1.581)$ & 0.657 & $0.745(0.393-1.412)$ & 0.367 \\
\hline Severe $\mathrm{CI}^{\mathrm{b}}$ & $1.041(0.642-1.688)$ & 0.872 & $1.195(0.697-2.049)$ & 0.517 \\
\hline Psychiatric disease $^{c}$ (No, ref.) & $1.299(0.524-3.220)$ & 0.572 & $1.250(0.479-3.258)$ & 0.648 \\
\hline Delusions (No, ref.) & $1.755(1.092-2.820)$ & $\mathbf{0 . 0 2 0}$ & $2.082(1.199-3.613)$ & 0.009 \\
\hline Wandering (No, ref.) & $1.609(0.987-2.623)$ & 0.057 & $1.523(0.882-1.630)$ & 0.131 \\
\hline
\end{tabular}


Table 3 (continued)

\begin{tabular}{|c|c|c|c|c|}
\hline & \multicolumn{2}{|c|}{$\begin{array}{l}\text { Univariable logistic regression } \\
\text { model }\end{array}$} & \multicolumn{2}{|c|}{$\begin{array}{l}\text { Multivariable logistic regression } \\
\text { model }\end{array}$} \\
\hline & OR $(95 \% \mathrm{CI})$ & $p$ value & OR $(95 \% \mathrm{CI})$ & $p$ value \\
\hline Resistance to care (No, ref.) & $0.674(0.417-1.088)$ & 0.106 & $0.451(0.258-0.788)$ & 0.005 \\
\hline Constant & & & $0.019(0.003-0.129)$ & $<0.001$ \\
\hline \multicolumn{5}{|l|}{ Anxiolitics } \\
\hline Facility type $^{\mathrm{a}}$ (NH ref.) & $1.123(0.746-1.692)$ & 0.578 & $1.115(0.697-1.784)$ & 0.649 \\
\hline Gender (female ref.) & $1.023(0.656-1.596)$ & 0.920 & $1.027(0.620-1.703)$ & 0.917 \\
\hline Age & $1.006(0.989-1.024)$ & 0.470 & $1.008(0.989-1.028)$ & 0.390 \\
\hline Mild CI (ref.) & 1 & & 1 & \\
\hline Moderate $\mathrm{CI}^{\mathrm{b}}$ & $0.573(0.320-1.026)$ & 0.061 & $0.528(0.289-0.966)$ & 0.038 \\
\hline Severe $\mathrm{CI}^{\mathrm{b}}$ & $0.893(0.568-1.405)$ & 0.626 & $0.796(0.483-1.312)$ & 0.371 \\
\hline Agitation (No, ref.) & $1.558(1.011-2.401)$ & 0.044 & $1.452(0.882-2.389)$ & 0.142 \\
\hline Hallucinations (No, ref.) & $1.616(0.954-2.736)$ & 0.074 & $1.584(0.888-2.826)$ & 0.119 \\
\hline Regular contact with family (No, ref.) & $0.774(0.512-1.169)$ & 0.223 & $0.774(0.485-1.233)$ & 0.280 \\
\hline Verbal abuse (No, ref.) & $1.972(1.172-3.317)$ & 0.010 & $1.358(0.820-2.252)$ & 0.235 \\
\hline Constant & & & $0.212(0.042-1.079)$ & 0.062 \\
\hline \multicolumn{5}{|l|}{ Hydroxizine } \\
\hline Facility type $^{\mathrm{a}}$ (NH ref.) & $1.197(0.755-1.897)$ & 0.445 & $0.976(0.559-1.703)$ & 0.931 \\
\hline Gender (female ref.) & $0.968(0.586-1.599)$ & 0.899 & $0.957(0.534-1.715)$ & 0.884 \\
\hline Age & $1.012(0.992-1.032)$ & 0.242 & $1.016(0.993-1.039)$ & 0.187 \\
\hline Mild $\mathrm{CI}^{\mathrm{b}}$ (ref.) & 1 & & 1 & \\
\hline Moderate $\mathrm{CI}^{\mathrm{b}}$ & $0.650(0.335-1.263)$ & 0.204 & $0.486(0.181-1.302)$ & 0.151 \\
\hline Severe $\mathrm{CI}^{\mathrm{b}}$ & $1.039(0.626-1.724)$ & 0.883 & $0.465(0.188-1.150)$ & 0.097 \\
\hline Other dementia (No, ref.) & $0.825(0.519-1.312)$ & 0.417 & $0.735(0.443-1.218)$ & 0.232 \\
\hline Hallucinations (No, ref.) & $1.637(0.921-2.910)$ & 0.093 & $1.693(0.880-3.256)$ & 0.115 \\
\hline Aggressive behaviour $(\mathrm{ABS})^{\mathrm{d}}$ (No, ref.) & $1.467(0.922-2.333)$ & 0.106 & $0.665(0.288-1.539)$ & 0.341 \\
\hline Chair preventing rising ${ }^{\mathrm{e}}$ (No, ref.) & $0.543(0.237-1.244)$ & 0.149 & $0.444(0.177-1.116)$ & 0.084 \\
\hline Regular contact with family (No, ref.) & & & $0.577(0.337-0.988)$ & 0.045 \\
\hline Mild CI × Aggressive behaviour (ABS) & - & - & 1 & \\
\hline Moderate $\mathrm{CI} \times$ Aggressive behaviour (ABS) & - & - & $2.528(0.611-10.454)$ & 0.200 \\
\hline Severe $\mathrm{CI} \times$ Aggressive behaviour $(\mathrm{ABS})$ & - & - & $4.591(1.377-15.300)$ & 0.013 \\
\hline Constant & & & $0.144(0.021-0.986)$ & 0.048 \\
\hline
\end{tabular}

Values for which $p<0.05$ are highlighted in bold

${ }^{a}$ Facility type ( $N H$ nursing home, $R H$ residential home)

${ }^{\mathrm{b}}$ Cognitive performance scale (CPS): mild cognitive impairment $(\mathrm{CPS}=2)$, moderate cognitive impairment $(\mathrm{CPS}=3-4)$, and severe cognitive impairment (CPS $=5-6)$

${ }^{\mathrm{c}}$ Psychiatric diseases except depression and dementia

${ }^{\mathrm{d}}$ Aggressive Behaviour Scale (ABS): no signs of aggressive behavior (0), any sign of aggressive behaviors (1-12)

${ }^{\mathrm{e}}$ Chair preventing rising: armchair with strips to prevent uncontrolled rising or falling

light of current research, because they are ineffective in both vascular dementia $(\mathrm{VaD})[25,26]$ and Lewy body dementia (DLB) [27]. These findings indicate that prescribing of ADM may be suboptimal especially in mild-to-moderate stages of dementia. More in depth study is needed to shed more light on potential reasons of that, e.g. financial limitations, administrative obstacles, or simply lack of knowledge on diagnosis and treatment of dementia.

\section{Use of typical and atypical antipsychotic drugs}

Based on a systematic review by Janus et al. [28], the rates of use of APM in Western and Nordic European NHs range from 12 to 59\% with the highest in Austria, Ireland and Belgium. In the SHELTER study conducted in $57 \mathrm{NHs}$ in 8 European countries, $26.4 \%$ of all NH residents [29], and $35.6 \%$ of residents with severe CI [30] were treated with 
antipsychotics (in 2010). In the US, this percentage was much lower than in Europe with tendency to decline-in 14.6\% of all residents, and $24.8 \%$ of dementia patients in NHs (in the year 2014) [31]. In light of these data, our results look dramatic-antipsychotics were prescribed to $46.4 \%$ of $\mathrm{RH}$ and $\mathrm{NH}$ residents with CI. There was only one other study on use of these medicines in Poland-it showed similarly high rates of antipsychotics use (43.4\%) in NH residents with moderate and severe dementia (in 2013) [32]. During the last decade, the use of A-APM has gradually been replacing typical neuroleptics, nevertheless number of residents treated with T-APM is still very high (27.9\% in our study), even though this class of medicines should be avoided due to extrapyramidal and cholinolytic side effects. Multivariable regression analysis showed that prescribing A-APM is more probable in older residents, and when delusions appear. In contrary, there was no factor increasing the odds of T-APM use. The last finding may suggest that there is no clear pattern of prescribing of these drugs, which may mean that physicians in LTCIs do not follow clinical recommendations.

\section{Use of anxiolytics}

Compared to SHELTER study (where $36.0 \%$ of residents used benzodiazepines), the use of all anxiolytics in our LTCIs was lower (28.4\% residents) with definitively lower usage of long acting benzodiazepines ( $4.4 \%$ of residents with CI) and hypnotics (short acting benzodiazepines and z-drugs in $6.2 \%$ of CI residents). However, $20.2 \%$ of studied residents $(71.3 \%$ of all individuals taking any anxiolytic drug) received hydroxyzine, which according to Beers criteria should be avoided in older patients, especially in $\mathrm{AD}$, dementia or other CI. We showed that aggressive behaviors in patients with severe CI might increase the risk of administering this medicine 2.6 times, despite the fact that it is a potentially inappropriate drug due to highly anticholinergic effects causing risk of confusion and cognitive decline [33]. It is worth noting that regular contact with family might reduce that risk by almost half.

\section{Use of physical restraints}

There is robust literature that physical restraints are measures involving deprivation of liberty, which are associated with deaths and suppression in quality of life. Nevertheless, in our study, the use of restrictive devices as full bed rails was very common $(57.1 \%)$, which is probably caused by the general belief of the staff that these are means of protecting the bedridden patients from falling out of bed. The use of other physical restraints was much less frequent (5.4\% trunk restraints, and $12.3 \%$ chair preventing rising). However, taking into account that each use of them is strictly regulated and very limited by law, these proportions should be evaluated as relatively high.
We thought that pharmacological and physical restraints may be used together or interchangeably in dementia residents presenting NPS, but statistical analysis did not confirm that. We had conducted analysis including use of each type of physical restraints (the full bed rails, trunk restraints, chair preventing rising) separately and all together as one variable in the logistic regression models, however, we did not find any significant association between use of them and any of psychotropic class.

\section{Drugs prescribing practice in the LTC residents with cognitive impairment}

As a result of the logistic regression analysis, we have received a clear message that Alzheimer's disease is an independent predictor of ADM use, while other dementia increases the risk of prescribing OP (nootropic drugs). However, the level of CI had no impact on use of specific psychotropic drugs with an exception for anxiolytics (odds for their use was lower in moderate CI). In contrary, the presence of psychotic symptoms or aggressive behaviors increased the use of some of psychotropics. Brimelow et al. [34] also reported that agitation and psychotic symptoms in residents with dementia increased the prescribing of psychotropic medicines more than twice. Thus, it seems that the presence of certain symptoms is the main trigger to prescribe these drugs, not the diseases themselves.

In addition to the regression analysis, which provided us with information about determinants of use of certain drug classes separately, we examined if there are some classes of psychotropic drugs used together (or not). As a result of MCA we have gained better insight into how the residents with mild, moderate and severe CI are treated in LTCIs. We found that taking A-APM was often combined with using anxiolytics, but not T-APM, and it applied more often to the oldest residents (aged 85 years and older) (a gray circle, Fig. 1). In opposite, the residents who were administrated with T-APM, more often had moderate CI, and less frequently received A-APM and anxiolytics (a yellow circle, Fig. 1). In turn, taking OP was rather correlated with residing in $\mathrm{NH}$, severe $\mathrm{CI}$ and being aged $75-84$ years (a green circle, Fig. 1). Contrary to that, having mild CI and residing in $\mathrm{RH}$ was not related to more frequent taking of any psychotropic medications.

\section{Strengths and limitations}

This is an epidemiological cross-sectional study, which in contrary to longitudinal study design cannot explain causeeffect relation between symptoms and drugs use. However, it is worth highlighting, that this is the first national research of the CI residents' treatment in a country-representative 
sample of NHs and RHs in Poland conducted with use of a tool allowing comparisons with other countries in Europe and US. It showed some differences compared with other countries (lower use of anxiolytics and much higher use of antipsychotics), as well as revealed factors associated with taking these drugs. We focused on associations between resident characteristics and use of drugs from certain classes, and found that physicians taking care for LTC residents did not follow clinical recommendations for CI treatment, properly. We found the differences of prescribing practices between GPs providing care in RHs and physicians employed in NHs, however, due to lack of information about their specialties we could not conduct more in depth analysis to find if their knowledge and experience had impact on the type of treatment.

This paper points out the main treatment issues, which should be corrected to assure good quality of care. It provides some prompts for education of the physicians working in LTCIs, who often have different specialization background (not necessarily geriatrics). The rate of geriatricians in our country is one of the lowest in EU ( 0.06 per 1000 persons at age 65 and over), and most of them work in acute geriatric wards. Therefore, physicians working in LTC facilities, both GP and other specialists, definitely need training to improve their prescribing practice.

\section{Conclusions}

In our study, we examined factors associated with prescribing ADM, A-APM, T-APM, anxiolytics and OP in the individuals with CI residing in LTCIs. We found that use of ADM was less frequent than in US and in other countries. Patients with AD had a higher chance of receiving ADM, while patients with other dementia-OP. Almost half of LTC residents with CI received antipsychotics, which is significantly higher than in other European and North American countries. In contrary, use of anxiolytics was much lower. We found that some NPSs (delusions, aggressive behavior), were significantly associated with higher use of some psychotropics. Moreover, we have observed specific prescribing practices correlated with residents' age, CI level and facility type. We found that oldest residents more often used A-APM (compared to T-APM) and anxiolytics, while NH residents aged 75-84 with severe CI more often were prescribed OP. In contrast, the residents with moderate $\mathrm{CI}$ more often resided in $\mathrm{NHs}$ and were administered with T-APM.

Our analyses confirmed that there are still many LTC residents who receive medications that are not recommended or even contraindicated in dementia (e.g. T-APM and hydroxyzine). Despite existing clinical recommendations for treatment of CI and NPSs, the physicians taking care for LTC residents do not follow them properly. Hence, more attention should be given to motivate physicians to change their prescribing practices to provide residents with adequate and effective treatment.

Acknowledgements The authors would like to thank the managers of long-term care facilities in Poland who allowed the study to be conducted in their centers, and to the facilities' nursing staff for participating in collecting the data.

Author contributions All authors participated in designing the study. VK formulated the research questions, designed the study, carried it out, collected the data, developed statistical analysis plan and wrote the article. IB was responsible for data management, the statistical design of the study and for carrying out the statistical analysis. KS designed the study, supervised the data collection, developed statistical analysis plan, assisted with interpretation of the results and supervised writing the article. All authors made substantial contribution to interpretation of data and critical revisions of the manuscript: VK, KS, IB.

Funding This work was supported by the Jagiellonian University Medical College (Grant no. K/DSC/003080).

\section{Compliance with ethical standards}

Conflict of interest The author(s) declared no potential conflicts of interest with respect to the research, authorship, and/or publication related to this article.

Ethical approval All procedures performed in studies involving human participants were in accordance with the ethical standards of the institutional and national research committee and with the 1964 Helsinki Declaration and its later amendments or comparable ethical standards. The authors declare that the study has been registered and accepted by Jagiellonian University Ethics Committee (agreement no. 122.6120.31.2015) and it was conducted in line of the current laws, meeting the standard requirements.

Informed consent Based on the Jagiellonian University Ethics Committee approval, the informed consent was obtained from all settings where the study was conducted. Data collected in the study were analyzed anonymously by researchers without any possibility of identification of individual residents.

Open Access This article is licensed under a Creative Commons Attribution 4.0 International License, which permits use, sharing, adaptation, distribution and reproduction in any medium or format, as long as you give appropriate credit to the original author(s) and the source, provide a link to the Creative Commons licence, and indicate if changes were made. The images or other third party material in this article are included in the article's Creative Commons licence, unless indicated otherwise in a credit line to the material. If material is not included in the article's Creative Commons licence and your intended use is not permitted by statutory regulation or exceeds the permitted use, you will need to obtain permission directly from the copyright holder. To view a copy of this licence, visit http://creativecommons.org/licenses/by/4.0/.

\section{References}

1. American Psychiatric Association (2013) Diagnostic and statistical manual of mental disorders. American Psychiatric 
Association. https://doi.org/10.1176/appi.books.9780890425 596

2. Lyketsos CG, Steinberg M, Tschanz JT, Norton MC, Steffens DC, Breitner JC (2000) Mental and behavioral disturbances in dementia: findings from the cache county study on memory in aging. Am J Psychiatry 157:708-714. https://doi.org/10.1176/ appi.ajp. 157.5 .708

3. Preuss U, Wong J, Koller G (2016) Treatment of behavioral and psychological symptoms of dementia: a systematic review. Psychiatr Pol 50:679-715. https://doi.org/10.12740/PP/64477

4. Onder G, Carpenter I, Finne-Soveri H, Gindin J, Frijters D, Henrard JC et al (2012) Assessment of nursing home residents in Europe: the Services and Health for Elderly in Long TERm care (SHELTER) study. BMC Health Serv Res 12:5. https://doi. org/10.1186/1472-6963-12-5

5. Seitz D, Purandare N, Conn D (2010) Prevalence of psychiatric disorders among older adults in long-term care homes: a systematic review. Int Psychogeriatrics 22:1025-1039. https://doi. org/10.1017/S1041610210000608

6. Kijowska V, Szczerbińska K (2018) Prevalence of cognitive impairment among long-term care residents: a comparison between nursing homes and residential homes in Poland. Eur Geriatr Med 9:467-476. https://doi.org/10.1007/s4199 9-018-0062-2

7. Schneider LS, Dagerman KS, Insel P (2005) Risk of death with atypical antipsychotic drug treatment for dementia: meta-analysis of randomized placebo-controlled trials. J Am Med Assoc 294:1934-1943. https://doi.org/10.1001/jama.294.15.1934

8. Herrmann N, Lanctôt KL (2005) Do atypical antipsychotics cause stroke? CNS Drugs 19:91-103. https://doi. org/10.2165/00023210-200519020-00001

9. Rochon PA, Normand SL, Gomes T, Gill SS, Anderson GM, Melo M et al (2008) Antipsychotic therapy and short-term serious events in older adults with dementia. Arch Intern Med 168:1090-1096. https://doi.org/10.1001/archinte.168.10.1090

10. Hyttinen V, Jyrkkä J, Valtonen H (2016) A systematic review of the impact of potentially inappropriate medication on health care utilization and costs among older adults. Med Care 54:950964. https://doi.org/10.1097/MLR.0000000000000587

11. Heider D, Matschinger H, Meid AD, Quinzler R, Adler JB, Günster C et al (2017) Health service use, costs, and adverse events associated with potentially inappropriate medication in old age in germany: retrospective matched cohort study. Drugs Aging 34:289-301. https://doi.org/10.1007/s40266-017-0441-2

12. Kijowska V, Barańska I, Szczerbińska K (2019) Health, functional, psychological and nutritional status of cognitively impaired long-term care residents in Poland. Eur Geriatr Med 2019:1-13. https://doi.org/10.1007/s41999-019-00270-5

13. Sanford AM, Orrell M, Tolson D, Abbatecola AM, Arai H, Bauer JM et al (2015) An international definition for "nursing home". J Am Med Dir Assoc 16:181-184. https://doi. org/10.1016/j.jamda.2014.12.013

14. Morris JN, Fries BE, Mehr DR, Hawes C, Phillips C, Mor $\mathrm{V}$ et al (1994) MDS cognitive performance scale. J Gerontol 49:M174-M182

15. Hirdes JP, Ljunggren G, Morris JN, Frijters DH, Finne Soveri H, Gray L et al (2008) Reliability of the interRAI suite of assessment instruments: a 12-country study of an integrated health information system. BMC Health Serv Res 8:277. https://doi. org/10.1186/1472-6963-8-277

16. Morris J., Belleville-Taylor P, Fries B., Hawes C, Murphy K, Mor V et al (2009) InterRAI long-term care facilities (LTCF) assessment form and user's manual. Version 9.1. Washington, DC: interRAI

17. Jones K, Perlman CM, Hirdes JP, Scott T (2010) Screening cognitive performance with the resident assessment instrument for mental health cognitive performance scale. Can J Psychiatry 55:736-740. https://doi.org/10.1177/070674371005501108

18. Hartmaier SL, Sloane PD, Guess HA, Koch GG, Mitchell CM, Phillips CD (1995) Validation of the minimum data set cognitive performance scale: agreement with the mini-mental state examination. J Gerontol A Biol Sci Med Sci 50:M128-M133. https://doi.org/10.1093/gerona/50a.2.m128

19. Gruber-Baldini AL, Zimmerman SI, Mortimore E, Magaziner J (2000) The validity of the minimum data set in measuring the cognitive impairment of persons admitted to nursing homes. J Am Geriatr Soc 48:1601-1606. https://doi. org/10.1111/j.1532-5415.2000.tb03870.x

20. Morris JN, Fries BE, Morris SA (1999) Scaling ADLs within the MDS. J Gerontol A Biol Sci Med Sci 54:M546-M553. https ://doi.org/10.1093/gerona/54.11.m546

21. Perlman CM, Hirdes JP (2008) The aggressive behavior scale: a new scale to measure aggression based on the minimum data set. J Am Geriatr Soc 56:2298-2303. https://doi.org/10.111 1/j.1532-5415.2008.02048.x

22. Burrows A, Morris JN, Simon SE, Hirdes JP, Phillips C (2000) Development of a minimum data set-based depression rating scale for use in nursing homes. Age Ageing 29:165-172. https ://doi.org/10.1093/ageing/29.2.165

23. WHO Collaborating Centre for Drug Statistics Methodology (2018) Guidelines for ATC classification and DDD assignment 2019. Oslo, Norway, 2018

24. Seitz DP, Gruneir A, Conn DK, Rochon PA (2009) Cholinesterase inhibitor use in US nursing homes: results from the national nursing home survey. J Am Geriatr Soc 57:2269-2274. https:// doi.org/10.1111/j.1532-5415.2009.02552.x

25. Farooq MU, Min J, Goshgarian C, Gorelick PB (2017) Pharmacotherapy for vascular cognitive impairment. CNS Drugs 31:759-776. https://doi.org/10.1007/s40263-017-0459-3

26. Szatmári S, Whitehouse P (2003) Vinpocetine for cognitive impairment and dementia. Cochrane Database Syst Rev 2003:003119. https://doi.org/10.1002/14651858.CD003119

27. Stinton C, McKeith I, Taylor J-P, Lafortune L, Mioshi E, Mak E et al (2015) Pharmacological management of Lewy body dementia: a systematic review and meta-analysis. Am J Psychiatry 172:731-742. https://doi.org/10.1176/appi.ajp.2015.14121 582

28. Janus SIM, van Manen JG, Ijzerman MJ, Zuidema SU (2016) Psychotropic drug prescriptions in Western European nursing homes. Int Psychogeriatrics 28:1775-1790. https://doi.org/10.1017/S1041 610216001150

29. Onder G, Liperoti R, Fialova D, Topinkova E, Tosato M, Danese $P$ et al (2012) Polypharmacy in nursing home in Europe: results from the SHELTER Study. Journals Gerontol Ser A Biol Sci Med Sci 67A:698-704. https://doi.org/10.1093/gerona/glr233

30. Vetrano DL, Tosato M, Colloca G, Topinkova E, Fialova D, Gindin J et al (2013) Polypharmacy in nursing home residents with severe cognitive impairment: results from the SHELTER Study. Alzheimer's Dement 9:587-593. https://doi.org/10.1016/j. jalz.2012.09.009

31. Maust DT, Kim HM, Chiang C, Kales HC (2018) Association of the centers for medicare $\&$ medicaid services' national partnership to improve dementia care with the use of antipsychotics and other psychotropics in long-term care in the United States from 2009 to 2014. JAMA Intern Med 178:640. https://doi.org/10.1001/jamai nternmed.2018.0379

32. Horwath U, Szczerbińska K (2019) Treatment of behavioral symptoms and unsettled relationships in clinically complex residents in the long-term care facility. Eur Geriatr Med 10:107-117. https ://doi.org/10.1007/s41999-018-0127-2

33. Fick DM, Semla TP, Steinman M, Beizer J, Brandt N, Dombrowski R et al (2019) American geriatrics society 2019 updated 
AGS beers criteria ${ }^{\circledR}$ for potentially inappropriate medication use in older adults. J Am Geriatr Soc 67:674-694. https://doi. org/10.1111/jgs. 15767

34. Brimelow RE, Wollin JA, Byrne GJ, Dissanayaka NN (2019) Prescribing of psychotropic drugs and indicators for use in residential aged care and residents with dementia. Int Psychogeriatrics 31:837-847. https://doi.org/10.1017/S1041610218001229

Publisher's Note Springer Nature remains neutral with regard to jurisdictional claims in published maps and institutional affiliations. 